\title{
Development of HVAC Diffuser Unit for Task and Ambient Air Conditioning Allowing User to Control Built-in Fan - Evaluation of Air Supply Mode by Subjective Experiment and Field Measurement in Office
}

\author{
Takashi Akimoto ${ }^{1,{ }^{*}}$, Naoya Odagiri ${ }^{1}$, Yoichi Nakashima $^{2}$, Seiji Miyazaki ${ }^{3}$, Takashi Yanai ${ }^{4}$, Takashi Matsumoto ${ }^{4}$, Daiki \\ Yamashina $^{4}$, and Nana Araki ${ }^{4}$ \\ ${ }^{1}$ Shibaura Institute of Technology, 3-7-5 Toyosu, Koto-ku, Tokyo 135-8548 Japan \\ ${ }^{2}$ KUCHO GIKEN KOGYO Co., Ltd., Japan \\ ${ }^{3}$ KUKEN KOGYO Co., Ltd., Japan \\ ${ }^{4}$ NIHON SEKKEI, INC., Japan
}

\begin{abstract}
HVAC diffusers have been developed that have dual functions for task and ambient air conditioning. In this study, we evaluated comfort according to air supply mode, strong or fluctuation mode, through a subjective experiment. We found that the fluctuation mode maintained greater comfort for longer compared with the strong mode under continuous airflow exposure. Therefore, the fluctuation mode is considered suitable for long-duration use. Moreover, field measurements in an actual office showed that the fluctuation mode was superior in terms of both comfort and energy saving compared with conventional air conditioning.
\end{abstract}

\section{Introduction}

In recent office buildings, various changes such as diversification of work, free address system, lighting control using human sensor, power saving by OA equipment equipped with sleep mode, etc. are seen. What is noteworthy is the uneven distribution of internal heat load of air conditioning. In order to deal with this, it is expected to develop and use a system that can realize different thermal environments according to individual feeling and work situation. Task and ambient air conditioning system is one of systems that can solve the problem, and being studied by many researchers ${ }^{1,2), 3)}$.

HVAC diffusers have been developed that have dual functions for task and ambient air conditioning. We conducted a verification experiment, subjective experiment, and field measurements in an actual office to understand the properties of the airflow from a task air conditioning system equipped with a new fluctuation mode. This paper describes the properties of this mode and evaluates the effects of the different air supply modes on comfort.

\section{HVAC system overview}

Figure 1 shows an overview of the TAC4 unit, which comprises four circular task diffusers with attached fans and one square ambient diffuser. Workers can use a remote control to set the task airflow to accommodate their individual thermal sensation via one of three operation patterns: strong mode, weak mode, and fluctuation mode. The task fan voltage is $24 \mathrm{~V}$ in strong mode, and $12 \mathrm{~V}$ in weak mode. In contrast, in fluctuation mode, the voltage fluctuates between $10 \mathrm{~V}$ and $20 \mathrm{~V}$ in 10-s cycles.

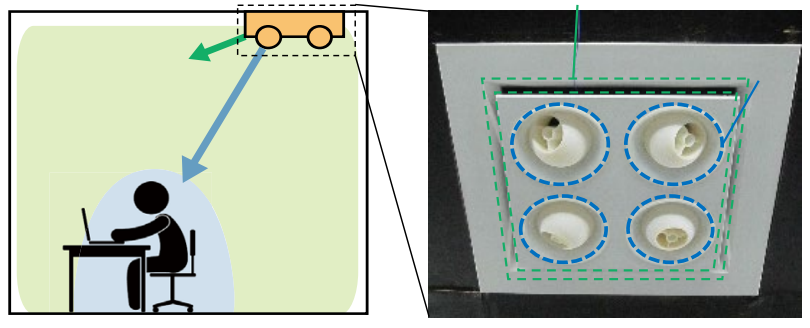

Fig. 1. TAC4 unit overview

\section{Measurement of task fan airflow properties}

\subsection{Overview}

To fully understand the properties of task airflow, we installed 16 non-directional hot-wire anemometers at a pitch of $200 \mathrm{~mm}$ to measure air velocity. Figure 2 shows an overview of our method for measuring airflow properties. We set the angle of the task diffusers to $45^{\circ}$ and turned on only one task fan for the target location.

*Corresponding author: akimoto@sic.shibaura-it.ac.jp 
We took measurements for each of strong mode, weak mode, and fluctuation mode from the seated position of a subject. We took 60 samples at a measurement interval of one second and a measurement height of FL $+900 \mathrm{~mm}$.
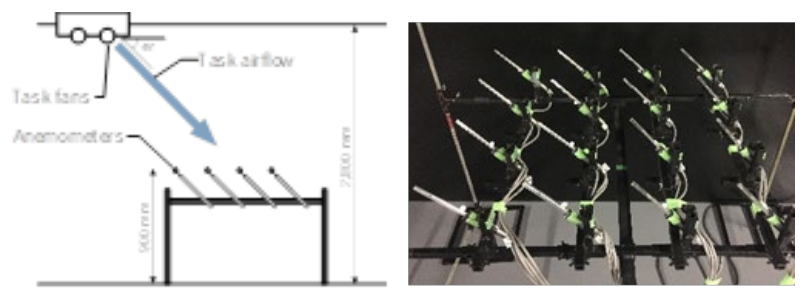

Fig. 2. Method of measuring airflow properties

\subsection{Measurement results}

Figure 3 is a distribution chart of air velocity maximums. Numbers shown in this figure are including rounding up errors. Table 1 shows the results of air velocity measurements. Figure 4 shows changes in air speed over time. Note that the task airflow in Figure 3 was supplied from the ceiling diffuser unit located toward the bottom of the figure, and that the air velocity values in Figure 4 are the maximums from the 16 measurement points.

The standard deviations from Table 1 and the distribution chart of air velocity maximums from Figure 3 show a greater range of fluctuation of the airflow axis of fluctuation mode than that of strong mode. Although there is fluctuation in the center of the airflow axis of fluctuation mode, we confirmed that it is less than 400 $\mathrm{mm}$ - within the range of exposure to the human body. Maximum air velocity of fluctuation mode is almost the same as average air velocity of strong mode.

In addition, when workers are able to adjust airflow, the maximum air speed - the thermal comfort zone (PMV \pm 0.5 ) - increases to $1.2 \mathrm{~m} / \mathrm{s}^{4}$ ). Our measured air speeds for both strong and fluctuation modes were less than 1.2 $\mathrm{m} / \mathrm{s}$, and thus were within the comfort zone (Figure 4).

\begin{tabular}{|c|c|c|c|} 
St rong mode \\
\hline $0 \%$ & $0 \%$ & $0 \%$ & $0 \%$ \\
\hline $0 \%$ & $0 \%$ & $2 \%$ & $0 \%$ \\
\hline $0 \%$ & $5 \%$ & $90 \%$ & $0 \%$ \\
\hline $0 \%$ & $2 \%$ & $2 \%$ & $0 \%$ \\
\hline
\end{tabular}

\begin{tabular}{|} 
Fluctuation mode \\
\hline $0 \%$ & $0 \%$ & $0 \%$ & $0 \%$ \\
\hline $0 \%$ & $0 \%$ & $3 \%$ & $0 \%$ \\
\hline $0 \%$ & $25 \%$ & $50 \%$ & $8 \%$ \\
\hline $0 \%$ & $3 \%$ & $12 \%$ & $2 \%$ \\
\hline
\end{tabular}

Fig. 3. Distribution of maximum air velocity

Table 1. Air velocity measurement results

\begin{tabular}{|c|c|c|c|}
\hline & $\begin{array}{c}\text { Average } \\
\text { air velocity }\end{array}$ & $\begin{array}{c}\text { Maximum } \\
\text { air velocity }\end{array}$ & $\begin{array}{c}\text { Standard } \\
\text { deviation }\end{array}$ \\
\hline Strong mode & $0.94 \mathrm{~m} / \mathrm{s}$ & $1.08 \mathrm{~m} / \mathrm{s}$ & 0.08 \\
\hline Fluctuation mode & $0.62 \mathrm{~m} / \mathrm{s}$ & $0.89 \mathrm{~m} / \mathrm{s}$ & 0.14 \\
\hline
\end{tabular}

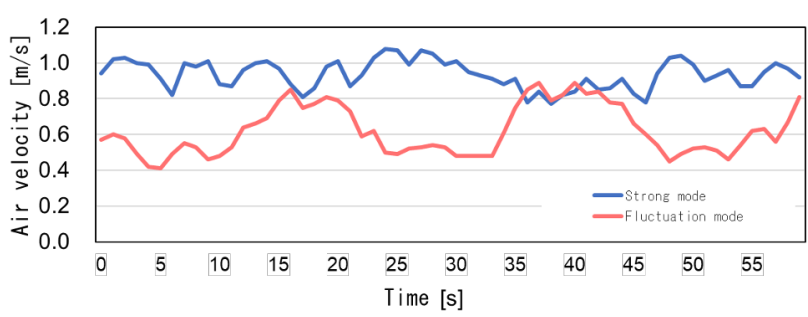

Fig. 4. Changes in air velocity over time

\section{Subjective experiment}

\subsection{Objective}

To verify the effects and capacity for maintaining comfort of the TAC4 unit's new fluctuation mode through an experiment that expose subjects to airflows over long periods of time.

\subsection{Experiment methods}

We conducted the subjective experiment in $\mathrm{K}$ Corporation's airflow laboratory in Fukuoka Prefecture. We asked the subjects to simulate the tasks of actual workers, and to report their experiences. Figure 5 is a floor plan of the laboratory and the measurement locations. Poles a-d measured the thermal environments within the subjects' task zones. We also measured skin surface temperatures at eight locations during the physiological survey.

For the psychological survey, we used reports regarding the basic information and life situations of subjects from Survey Form A, and subjective reports of their thermal sensation, comfort sensation, and airflow sensation following preceding papers ${ }^{3), 5)}$. Table 2 shows the experimental conditions, and Figure 6 shows the experiment schedule. Task airflow was constantly in strong mode in Case A and constantly in fluctuation mode in Case B.

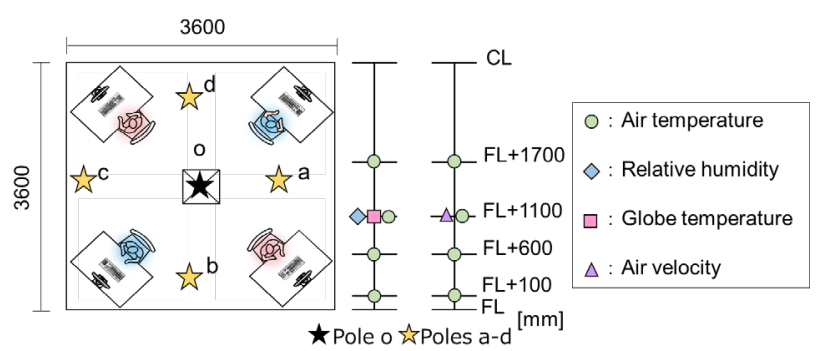

Fig. 5. Floor plan of experiment room and measurement 
Table 2. Experimental conditions

\begin{tabular}{|c|c|c|}
\hline Case & Case A & Case B \\
\hline Subjects & \multicolumn{2}{|c|}{6 males, 2 females } \\
\hline $\begin{array}{c}\text { Field } \\
\text { measurement } \\
\text { period }\end{array}$ & 5,7 August, 2017 & 8,9 August, 2017 \\
\hline $\begin{array}{c}\text { Room air } \\
\text { temperature }\end{array}$ & \multicolumn{2}{|c|}{$28^{\circ} \mathrm{C}$} \\
\hline $\begin{array}{c}\text { Clothing } \\
\text { value }\end{array}$ & $0.5 \mathrm{clo} \quad(\mathrm{Cool} \mathrm{Biz})$ \\
\hline $\begin{array}{c}\text { Supply air } \\
\text { temperature }\end{array}$ & \multicolumn{2}{|c|}{$12^{\circ} \mathrm{C}$} \\
\hline Task airflow & Strong mode & Fluctuation mode \\
\hline
\end{tabular}

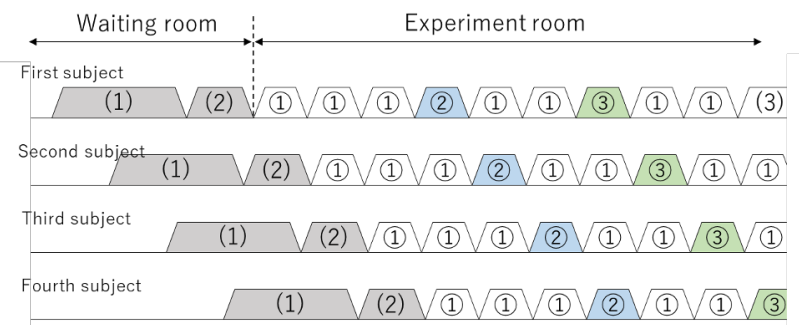

Fig. 6. Experiment schedule

First, we led subjects to a waiting room with the temperature set to $28^{\circ} \mathrm{C}$ to simulate an air-conditioned office. We let them acclimate for $45 \mathrm{~min}$ (1), and then had them do step-up exercises as they walked around the office at an activity rate of 1.7 met (2). Next, we led them to the experiment room to begin the experiment. We let one subject into the room every $10 \mathrm{~min}$. During the experiment, the subjects performed simulated office work and answered a questionnaire every $10 \mathrm{~min}$ (1). In addition, after answering questionnaires after 30 and 60 min in the room, we had them do step-up exercises at activity rates of 1.4 met (2) and 1.7 met (3) respectively.

\subsection{Results and discussion}

Table 3 shows a comparison of airflow comfort sensations for different time periods in Case A, and Figure 7 shows a comparison of airflow thermal sensation and comfort sensation for different time periods in Case A. Table 4 shows a comparison of airflow levels for different time periods in Case B, and Figure 8 shows a comparison of airflow thermal sensation and comfort sensation for different time periods in Case B. In both Case A and Case B, 81.3\% of subjects reported feeling comfortable 5-35 min after entering the experiment room. However, 45-90 min after entering the room, $72.2 \%$ of subjects in Case A reported comfort compared to $97.2 \%$ of Case B subjects; more subjects reported comfort with task airflow constantly in fluctuation mode. In addition, in Case A, reports of feeling cold or uncomfortable after $45-90 \mathrm{~min}$ in the room increased $6.6 \%$ from reports in the first 5-35 $\mathrm{min}$. In contrast, in Case B, some subjects reported feeling hot or uncomfortable in the first 5-35 $\mathrm{min}$ in the room, but none did so after 45-90 $\mathrm{min}$.
Our experiment shows that task airflow in fluctuation mode maintains or improves comfort under exposure for long periods of time, despite a feeling of insufficient cooling in the initial stages. These results demonstrate the effectiveness of fluctuation mode when task airflow is used for long periods of time.

Table 3. Airflow comfort levels for different time periods in Case A

\begin{tabular}{|c|c|c|c|}
\hline \multicolumn{2}{|c|}{$\begin{array}{c}\text { Time since entry into } \\
\text { experiment room }\end{array}$} & $5-35 \mathrm{~min}$ & $45-90 \mathrm{~min}$ \\
\hline Ratio of & Male & $79.2 \%$ & $80.0 \%$ \\
\cline { 2 - 4 } reports of & Female & $87.5 \%$ & $54.5 \%$ \\
\cline { 2 - 4 } comfort & Overall & $81.3 \%$ & $72.2 \%$ \\
\hline
\end{tabular}

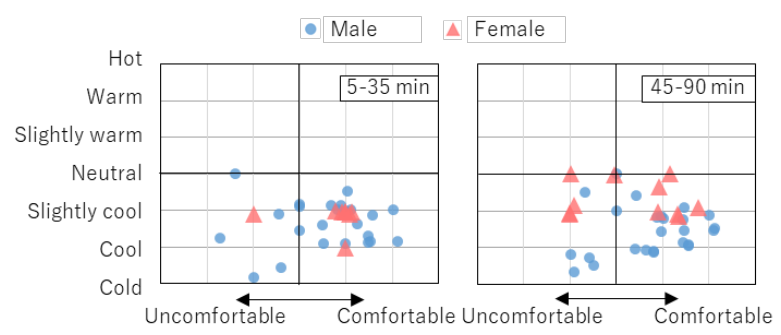

Fig. 7. Airflow thermal sensation and comfort sensation for different time periods in Case A

Table 4. Airflow comfort levels for different time periods in Case B

\begin{tabular}{|c|c|c|c|}
\hline \multicolumn{2}{|c|}{$\begin{array}{c}\text { Time since entry into } \\
\text { experiment room }\end{array}$} & $5-35 \mathrm{~min}$ & $45-90 \mathrm{~min}$ \\
\hline $\begin{array}{c}\text { Ratio of } \\
\text { reports of } \\
\text { comfort }\end{array}$ & Male & $75.0 \%$ & $96.0 \%$ \\
\cline { 2 - 4 } & Female & $100.0 \%$ & $100.0 \%$ \\
\hline
\end{tabular}

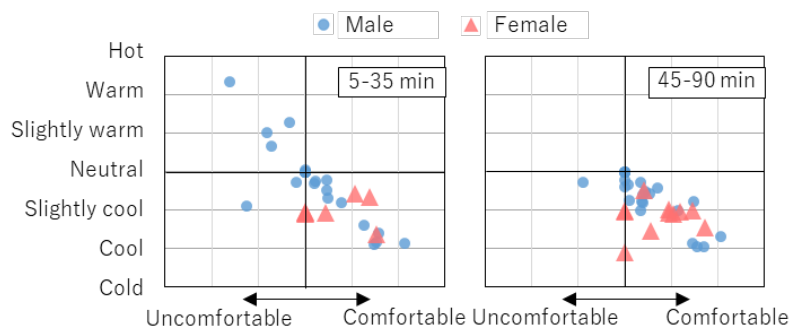

Fig. 8. Airflow thermal sensation and comfort sensation for different time periods in Case B

\section{Field measurements in an office}

\subsection{Objective}

To verify the effectiveness of task conditioning and study the state of its actual use, we investigated worker behaviour, questionnaire reports, the thermal environment, and electric power consumption. 


\subsection{Overview}

Table 5 provides an overview of the target building for our field measurements, and Figure 9 is a photograph of the interior of that building. A total of 12 TAC4 units are installed in the target building. Table 6 shows the conditions of the field measurements. It is worth noting that the energy recovery ventilators were operating in weak mode during the field measurement period.

Table 5. Overview of target building for field measurements

\begin{tabular}{|c|c|}
\hline Location & Itoshima, Fukuoka \\
\hline Function & Office \\
\hline $\begin{array}{c}\text { Year of } \\
\text { completion }\end{array}$ & 1989 \\
\hline Property area & $340.9 \mathrm{~m}^{2}$ \\
\hline $\begin{array}{c}\text { Target floor } \\
\text { area }\end{array}$ & $329.2 \mathrm{~m}^{2}$ \\
\hline $\begin{array}{c}\text { Number of } \\
\text { floors/structure }\end{array}$ & $\begin{array}{c}\text { 2 floors/steel } \\
\text { structure }\end{array}$ \\
\hline & $\begin{array}{c}\text { Pressurized ceiling } \\
\text { diffuser } \\
\text { (Total heat }\end{array}$ \\
& $\begin{array}{c}\text { exchanger, packaged air } \\
\text { conditioner) }\end{array}$ \\
\hline
\end{tabular}

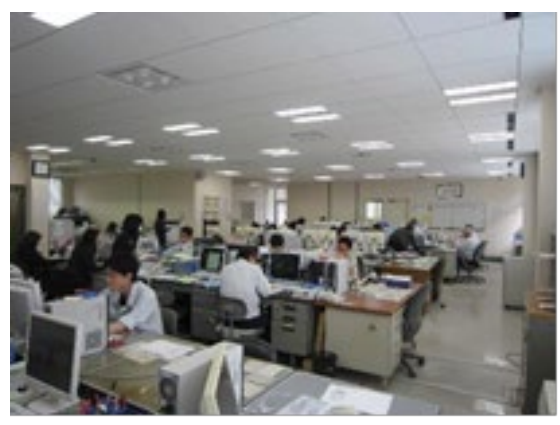

Fig. 9. Target office interior

Table 6. Field measurement conditions

\begin{tabular}{|c|c|c|c|}
\hline Case & $\begin{array}{c}\text { AC } \\
\text { temperature } \\
\text { setting }\end{array}$ & \multirow{2}{*}{$\begin{array}{c}\text { Task } \\
\text { operation }\end{array}$} & $\begin{array}{c}\text { Field } \\
\text { measurement } \\
\text { period }\end{array}$ \\
\hline 1 & $27^{\circ} \mathrm{C}$ & \multirow{2}{*}{ Yes } & $\begin{array}{c}4,7,9 \text { August, } \\
2017\end{array}$ \\
& & & $\begin{array}{c}3,5,8 \text { August, } \\
2017\end{array}$ \\
\hline 2 & $28^{\circ} \mathrm{C}$ & & \\
\hline
\end{tabular}

\subsection{Measurement Items}

Figure 10 shows the thermal environment measurement locations. Measurement items are listed on Table 7. The field survey involved a total of 20 workers: 10 males and 10 females. Our physiological survey comprised two parts. First, we attached an activity monitor (HJA-750C Active Style Pro, Omron; Figure 11) to the waist of each worker to measure their physical activity intensity (an indicator that expresses calories burned during activity or exercise as a multiple of calories burned at rest). We also visually measured the occupancy rate of chairs throughout the office, and used pressure sensors as chair sensors for more detailed measurements (Figure 12). For the psychological survey, we administered a questionnaire asking workers to report their thermal sensation, life situation, and health condition on that day, following preceding papers ${ }^{3), 5)}$ (Figure 13). We asked workers to give a total of five thermal sensation reports each day: one each at the beginning and end of the session, and one during each break.

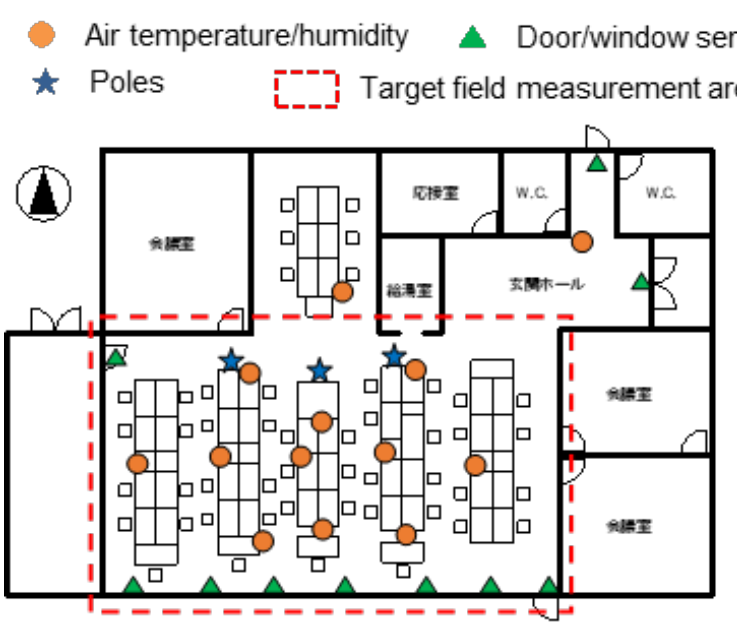

Fig. 10. Thermal environment measurement locations

Table 7. Measurement items

\begin{tabular}{|c|c|c|}
\hline \multirow{7}{*}{$\begin{array}{l}\text { Physical } \\
\text { environment }\end{array}$} & Measurement items & \multirow{4}{*}{ Poles } \\
\hline & $\begin{array}{l}\text { Horizontal air temperature/relative humidity distribution } \\
(0.6 \mathrm{~m})\end{array}$ & \\
\hline & $\begin{array}{l}\text { Vertical air temperature distribution } \\
(0.1,0.6,1.1,1.7,2.5 \mathrm{~m})\end{array}$ & \\
\hline & $\begin{array}{l}\text { Radiant temperature, relative humidity, air velocity } \\
(1.1 \mathrm{~m})\end{array}$ & \\
\hline & \multicolumn{2}{|c|}{$\begin{array}{l}\text { Air temperature/relative humidity at packaged air conditioner } \\
\text { and total heat exchanger outlet }\end{array}$} \\
\hline & \multicolumn{2}{|l|}{ Windows/doors open or closed } \\
\hline & \multicolumn{2}{|l|}{ Air flow rate through constant air volume unit } \\
\hline $\begin{array}{l}\text { Working } \\
\text { conditions }\end{array}$ & \multicolumn{2}{|l|}{ Seated (chair sensors: 20, visual: all) } \\
\hline Electric power & \multicolumn{2}{|l|}{ Task fan voltage } \\
\hline consumption & \multicolumn{2}{|l|}{ AC system electric power consumption } \\
\hline $\begin{array}{l}\text { Physiological } \\
\end{array}$ & \multicolumn{2}{|l|}{ Activity level, number of steps } \\
\hline Psychological & \multicolumn{2}{|c|}{$\begin{array}{l}\text { Life situations, health condition on measurement day, therma } \\
\text { sensation reports }\end{array}$} \\
\hline
\end{tabular}

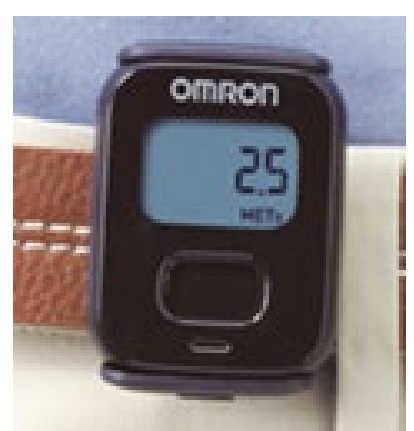

Fig. 11. Activity monitor

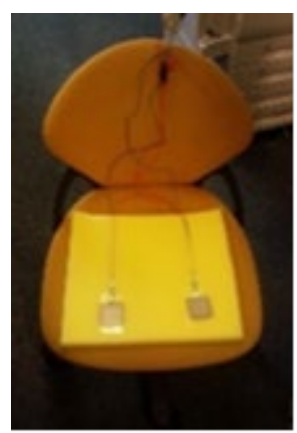

Fig. 12. Chair sensor 


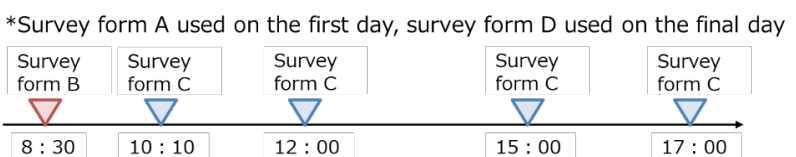

Survey form A: Life situations

Survey form B: health condition, thermal sensation reports

Survey form C: thermal sensation reports

Survey form D: survey regarding fluctuation mode

Fig. 13. Psychological survey methodology

\subsection{Results and discussion}

\subsubsection{Thermal sensation reports}

Figure 14 shows breakdowns of overall and genderspecific thermal comfort reported by workers before and after fluctuation mode was turned on. In Case 1, turning on fluctuation mode resulted in an $11 \%$ decrease in overall reports of "Comfortable" and "Very comfortable" (61\%), but if reports of "Neutral" are included, the rate held steady at $90 \%$. Although the proportion of reports of "Comfortable" or better decreased, reports of "Uncomfortable" or worse remained essentially the same. Likely factors were the $7 \%$ increase in task fan usage rate observed fluctuation mode was turned on, and our active efforts to create a favorable task thermal environment. In Case 2, turning on fluctuation mode resulted in a $10 \%$ increase in overall reports of "Comfortable" and "Very comfortable" (64\%).
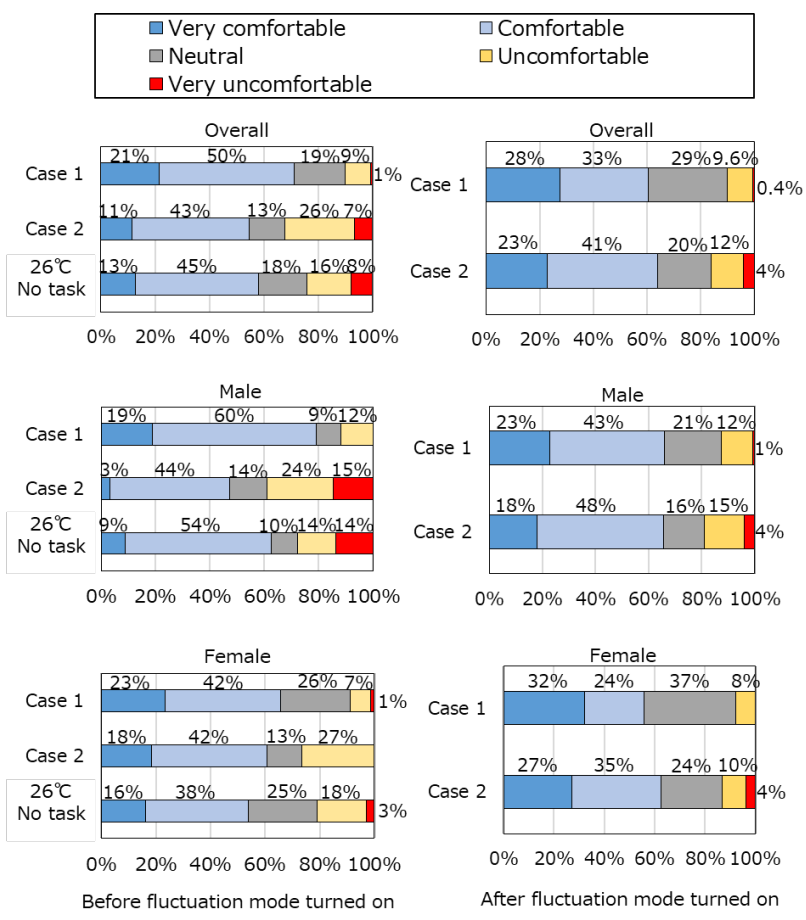

Fig. 14. Results of thermal sensation and thermal comfort reports with and without fluctuation mode

\subsubsection{Air conditioner electric power consumption}

Figure 15 shows a comparison of air conditioner electric power consumption in each case. We averaged the electric power consumption in each case from 7:0017:00 on each day during the field measurement period. For electric power consumption at [AC temperature setting $26^{\circ} \mathrm{C} /$ No task], we used the figures from our field measurements of the office before turning on fluctuation mode. In addition, because we lost the data for All-inOne Air Conditioning System 1, we calculated figures based on measurement data from a previous report. Turning on fluctuation mode resulted in a $19.5 \%$ decrease in electric power consumption in Case 1 and a $26.9 \%$ decrease in Case 2 compared to conventional air conditioners. This indicates that task air conditioning in fluctuation mode produces a demonstrable energy-saving effect.

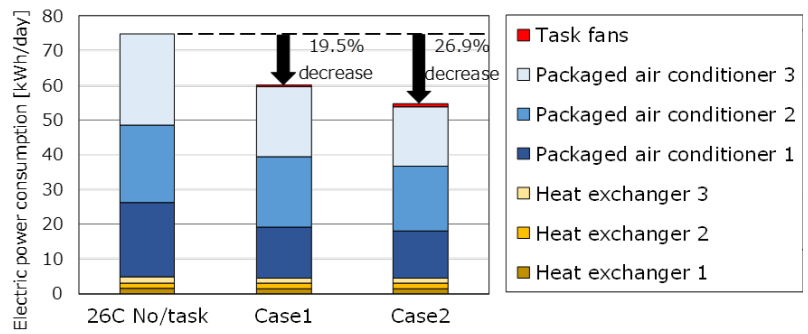

Fig. 15. Air conditioner electric power consumption by case

\subsubsection{Relationship between physical activity intensity and task fan operation mode}

Figure 16 shows the seated periods, physical activity intensity, and task fan operation status for male subject M2 on August 5. Figure 17 shows some of M2's thermal sensation reports throughout that day. Around 12:30, after a period of high-energy activity, M2 returned to his seat and switched his task fan to fluctuation mode. He reported feeling comfortable (Figure 17). As a person who set his task fan to weak mode on other days, M2's case suggests that fluctuation mode is suitable for use by people who prefer moderate airflow as an intermediate mode between weak and strong modes.

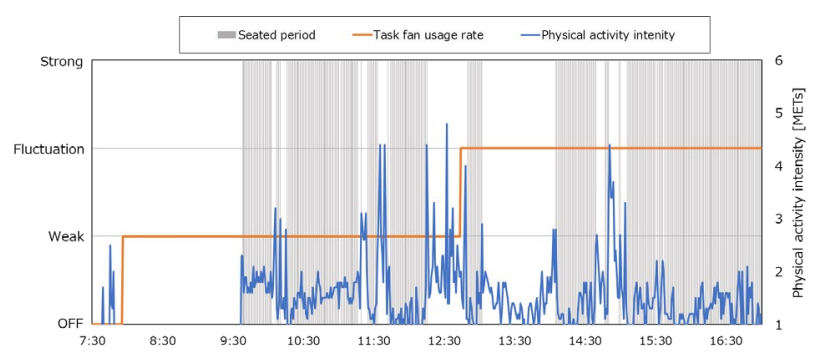

Fig. 16. Physical activity intensity/task fan operation status 


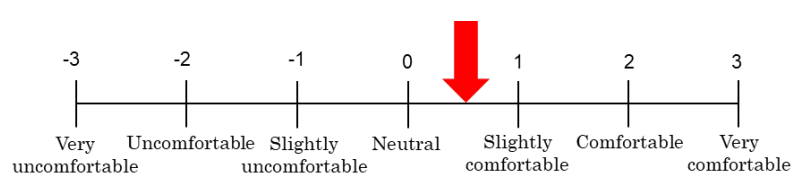

Fig. 17. Thermal sensation report results: August 5, daytime, male test subject M2

\section{Conclusions}

In our measurements of the properties of task fan airflow, we confirmed the fluctuation of axial flow in fluctuation mode compared to normal operation modes.

In thermal sensation reports from subjective experiments, we noted fewer reports of comfort in the second half of the experiment with the task fans in strong mode, but observed an increase of reports of comfort in the second half of the experiment with the task fans in fluctuation mode. This suggests that fluctuation mode is an appropriate air supply mode for the use of task fans over long periods.

In our field measurements in an office, we found that fluctuation mode reduced electric power consumption in both cases compared with conventional air conditioning, which indicates that task conditioning in fluctuation mode produces a demonstrable energy-saving effect. The results of thermal sensation reports improved after fluctuation mode was turned on in Case 2 [AC temperature setting $28^{\circ} \mathrm{C}$ ], the case with the highest task fan usage rate. The results also suggest that fluctuation mode is suitable for use as an intermediate mode between weak and strong modes.

\section{References}

1. Bauman F, Arens E. Task/ambient conditioning systems: engineering and application guidelines final report: 1996.

2. Zhang H, Arens E, Kim D, Buchberger E, Bauman F, Huizenga C. Comfort, perceived air quality, and work performance in a low-power task-ambient conditioning system. Building and Environment 45 (2010) 29-39.

3. Akimoto T, Tanabe S, Yanai T, Sasaki M. Thermal comfort and productivity - evaluation of workplace environment in a task conditioned office. Building and Environment 45 (2010) 45-50.

4. ASHRAE. 2013. ANSI/ASHRAE Standard 55-2013, Thermal environmental conditions for human occupancy. Atlanta: Ashrae, Inc.

5. Takata M, Yoshida K, Nakashima Y, Yanai T, Matsumoto T, Akimoto T. Development of HVAC diffuser unit for task and ambient conditioning allowing user to control built-in fan: Part 4 Physiological and psychological responses of human subjects. Summaries from the conference of the Society of Heating, Air-Conditioning and Sanitary Engineers of Japan. (2016.9) 73-76 (in Japanese). 